CORRESPONDENCE

\title{
Research Article on "Estimation of carbon stocks in the forest plantations of Sri Lanka"
}

I write with reference to the above titled article published by W.A.J.M. de Costa and H.R. Suranga in the 2012 March issue of JNSF, 40(1): $9-41$.

The authors have worked out the total wood volume of different timber species of forest plantations in the Wet and Intermediate Zones of Sri Lanka. There are altogether 22 species of trees planted in monoculture and in mixed-cultures in 12 districts. Using the database on these plantations maintained by the Forest Department, Sri Lanka, the authors have computed separately the wood volumes of different tree species grown in each of these districts. They have converted these volumes, into tonnes using a common wood density value of $0.49 \mathrm{t} / \mathrm{m}^{3}$.

It is well known that timber species have different densities varying over a wide range of values. For local timber, densities have been found to vary from $413 \mathrm{~kg} / \mathrm{m}^{3}$ for Pinus caribea to $745 \mathrm{~kg} / \mathrm{m}^{3}$ for Tectona grandis as given in www.sjp.ac.lk/research/pdf/10-03-amarasekera- alternative-timber-construction (accessed 18 April 2012). The value of the article is reduced as a result of using a common density value for the conversion of volume to mass for the entire stock of trees. In particular Table 17 tabulates $\mathrm{C}$ stock per ha for different species in each of the districts. However, the use of species specific density values for the different species, would have made the calculated values more accurate and acceptable.

In climate change negotiations taking place in international fora, the role of forests as carbon sinks is often highlighted and the availability of high quantities of carbon stocks is often used as a strategy for compliance with obligations agreed upon at these fora. In this context, it is essential to have accurate figures for the total carbon stock in forest plantations in a country. While the efforts made by Costa and Suranga is highly appreciable the recalculation of the mass of timber stocks in forest plantations using species specific density values is a nationally important exercise.

Janaka Ratnasiri 